\section{A Source of Lithium Light}

A sTRONGER source of red light than that provided by the cadmium discharge lamp is desirable for rotatory dispersion measurements. Both lithium carbonate in a flame and lithium chloride in an are have been used to give the $6708 \mathrm{~A}$. line; but the first source lacks intensity and the second is unstable.

Attempts to produce a lithium lamp on the lines of the laboratory sodium lamp have proved abortive for a number of reasons, the chief of which appeared to be the action of hot lithium on glass. The availability of commercial argon in cylinders renders the use of a lithium metal are at normal pressure quite fessible. This source is both strong and sufficiently stable for polarimetric work. Fig. 1 shows the construction of the lamp. Both the useful lithium lines at $6708 \mathrm{~A}$. and at $6104 \mathrm{~A}$, are given.

Two points are worthy of note: (a) the 'Pyrex' glass shield is not attacked by the hot metal which distils on to the cooler parts; (b) the window is made of mica sheet, as an ordinary glass sheet cracks when the nose-piece of the polarimeter' is removed. from the aperture, due to the sudden advent of cold air.

The lamp in its present form requires cleaning after use (the finely divided metal can be removed with a

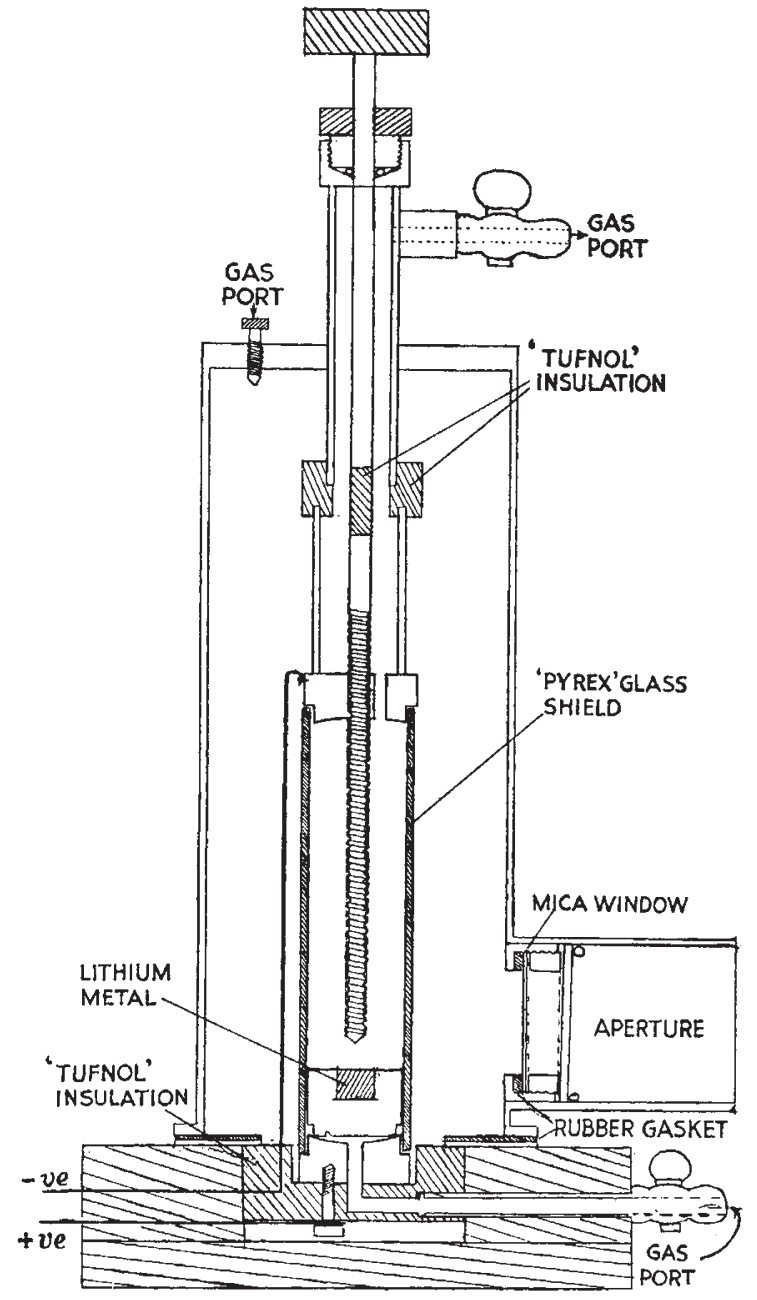

Fig. 1 rag), in which case the glass shield is apparently undamaged. If the metal is allowed to remain on the glass in air the glass is etched. Thus it seems that the difficulties encountered previously from the attacks of the hot metal were due to the presence of oxide or nitride on the surface of the metal. Cleaning of the lamp could be avoided in a commercial lamp by using an all-glass envelope with a magnetically operated screw for controlling the arc. The life of such a lamp would, however, be limited by the distillation of the metal on to the colder parts of the envelope. In view of the stability of glass to hot lithium metal in argon, it seems probable that further development of the normal laboratory-type lamp may now be possible.

\author{
Queen Elizabeth College \\ (University of London), \\ Campden Hill Road, \\ London, W.8. \\ Nov. 19
}

\section{K. Hargreaves}

\section{Gallium Oxide Glasses}

THe preparation and properties of some glasses based on the $\mathrm{CaO}-\mathrm{Al}_{2} \mathrm{O}_{3}$ system have already been described by one of us ${ }^{1}$.

Experiments which we have carried out more recently have shown that glasses can be made in the $\mathrm{CaO}-\mathrm{Al}_{2} \mathrm{O}_{3}$ system with alumina contents between 38 and 65 per cent. These glasses were melted on a scale of approximately $20 \mathrm{mgm}$. on a resistanceheated platinum alloy wire and were rapidly cooled by switching off the heating current. It is possible that the range of glass formation is even wider than has been indicated, for the limiting compositions were determined by the temperature at which the platinum alloy $(20$ per cent rhodium, 80 per cent platinum) wire melted. If an attempt is made to make these glasses on a larger scale, then it is necessary to add other oxides. In the work described in reference 1, it was found that if about 6 per cent silicon dioxide is added to the calcium aluminate melts then glasses can be made on a scale of many grams without difficulty. These glasses are characterized by fairly good transmission ${ }^{2}$ in the range 1-5 $\mu$. An infra-red absorption curve of a particular aluminate glass is shown in Fig. 1.

These results, together with our experience with other fundamentally new types of glass, encouraged us to study glass formation in the $\mathrm{CaO}-\mathrm{Ga}_{2} \mathrm{O}_{3}$ system, aluminium and gallium being in the same group of the Periodic Table.

The first step was to make microscale melts on the heated wire in the $\mathrm{CaO}-\mathrm{Ga}_{2} \mathrm{O}_{3}$ system. It was found that glasses could be made containing about 60 per cent of $\mathrm{Ga}_{2} \mathrm{O}_{3}$ but the range of glass formation was only a few per cent and the glasses devitrified even more readily than the aluminate glasses. As expected, the glasses became much more stable when silicon dioxide was added, and a glass of the composition $\mathrm{CaO} 33 \cdot 4, \mathrm{Ga}_{2} \mathrm{O}_{3} 59 \cdot 6$, and $\mathrm{SiO}_{2} 7$ per cent was made on a scale of approximately $5 \mathrm{gm}$. without much difficulty, although a glass containing 6 per cent silicon dioxide could not be made without some devitrification. The glasses were melted at $1,400^{\circ} \mathrm{C}$. for $1-2 \mathrm{hr}$. in platinum and were cast into disks. The glasses are yellowish-green in colour and have a refractive index of about 1.7. An infra-red absorption curve is shown in Fig. 1, and from this it may be seen 